\title{
Nutritive Value of Fruits in Vegetables is Decreasing Everyday
}

\author{
Aradhana Dixit* \\ Department of Home Science New Girls Degree College, Indore, India \\ Received: 非 August 01, 2018; Published: 制 August 08, 2018 \\ *Corresponding author: Aradhana Dixit, Department of Home Science New Girls Degree College, Indore, India
}

\section{Editorial}

Everyday i eat salads. But few hours back when i ate cucumber and carrot. I compared the same when I was in my Primary.

The taste has become Little blend as compared to its earlier sweet taste. The colour have become pale? while it used to be reddish. It left me with a thought -has nutritive value/ palatability/ acceptance of food has come down.

Earlier we used to play enough and eat a lot but now its opposite. Because there is no physical Exercise obesity amongst children is common. Reasons for nutritive value going down:

\section{Use of chemical free trees and Pesticides}

It has been departed so effecting nutrition and taste as well.

Remedy: Can we once again use manure? Wherein possible and replenish soil

\section{Breeding}

We are going for hybrids. To see more no create more refracture apples or oranges bigger in size. They are grown rapidly too but nutritionally may be Compromise.

Remedy: Can we go originals and hand in hand with nature?

\section{Processing}

Adding taste to buds. we put spices or overcoat for delicious Recepies. Add sugar and salt to preserve it.

Remedy: Can we cut down processed foods, sugar and salt?

\section{Use of fats}

We are so much health-conscious that on one side We avoid fats and on other hand eat junk foods remember fats are equally important for body function.

\section{Remedy}

Eat Fruits and carbs. in recommended amounts. Cut down saturated fats, Trans fat and cholesterol, the culprits. Eat MUFA and PUFA.

\section{Starving}

To reduce Weight its. better to give more output and burn calories than to starve.

Remedy: fit exercise like walks is best.

So, at glance use manure. Wherever possible, eat who naturally grown in lapse of nature, cut down processed food. salts, sugars, unwonted fats and Exercises!!

a) Go organic

b) Go nuts

c) Go green

d) Go original

e) Exercise

f) It works (Figure 1)

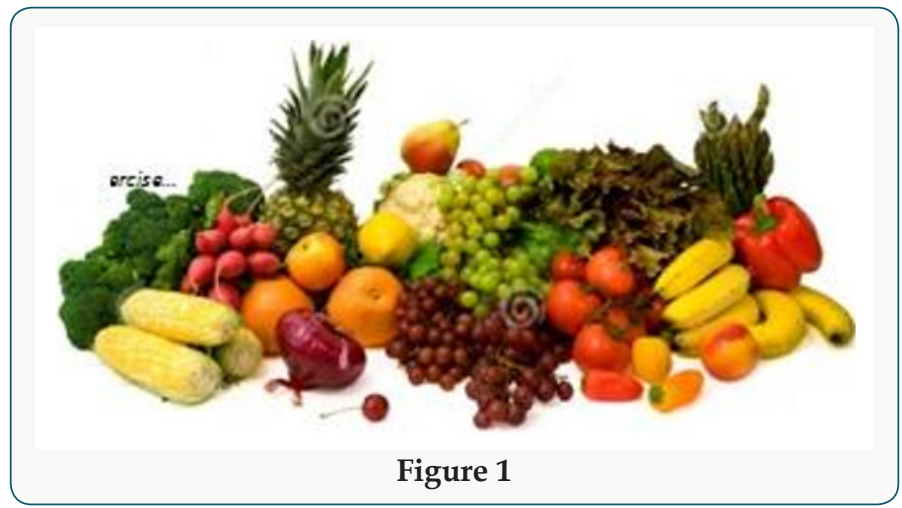




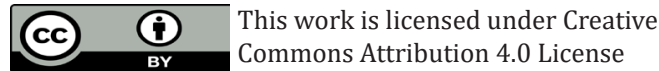

To Submit Your Article Click Here:

Submit Article

DOI: $10.32474 /$ LOJMS.2018.01.000101

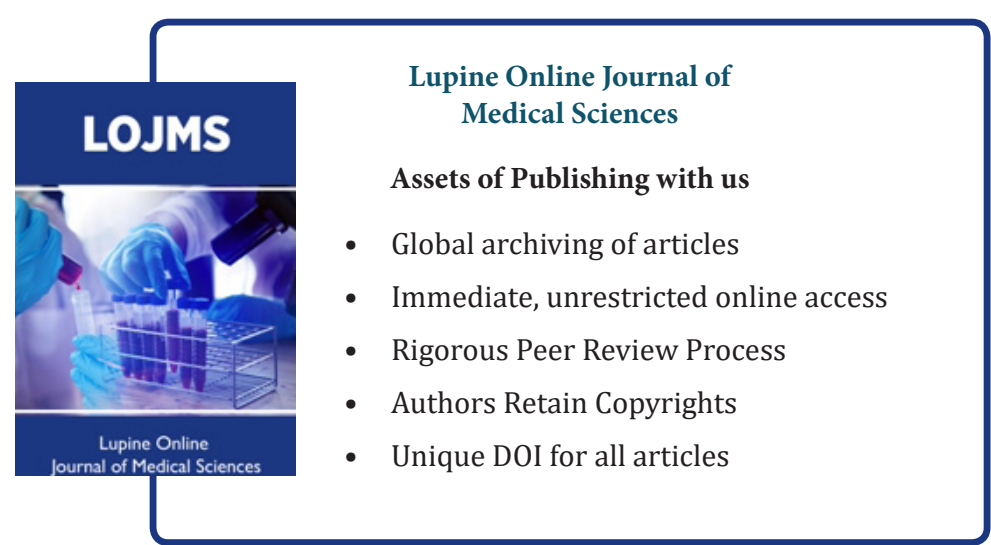

